I Universidade Federal do Rio de Janeiro (UFRJ),

Departamento de Sociologia e Programa de Pós-Graduação

em Sociologia e Antropologia, Rio de Janeiro, RJ, Brasil

andrebotelho@digirotas.com.br

https://orcid.org/oooo-o0oI-68I5-9040

I I Universidade Federal do Rio de Janeiro (UFRJ),

Departamento de Sociologia e Programa de Pós-Graduação

em Sociologia e Antropologia, Rio de Janeiro, RJ, Brasil

antoniobrasiljr@gmail.com

https://orcid.org/oooo-00oI-8653-668X

I I I Universidade Federal Rural do Rio de Janeiro (UFRRJ),

Departamento de Ciências Sociais, Seropédica, RJ, Brasil

mauriciohoelz@gmail.com

https://orcid.org/0000-0002-1392-0645

\title{
TÃO LONGE, TÃO PERTO: \\ SOCIOLOGIA \& ANTROPOLOGIA \\ NO LIMIAR DE UMA DÉCADA
}

Apresentamos um mapa semântico e bibliométrico da coleção de artigos de Sociologia \& Antropologia. Revista do PPGSA realizado a partir de metodologias informacionais, em particular o uso de certos métodos e técnicas de análise que se vêm difundindo em decorrência dos estudos bibliométricos e cientométricos.

Publicada pelo Programa de Pós-Graduação em Sociologia e Antropologia da Universidade Federal do Rio de Janeiro (PPGSA/UFRJ), desde 20 I I, a revista se vem consolidando na última década como um dos periódicos mais importantes de veiculação da produção científica de ponta das ciências sociais no Brasil. Nesse relativamente curto período, tanto testemunhou mudanças significativas na sociedade brasileira, e noutras em escala global, como protagonizou mudanças fundamentais no campo das ciências sociais, incluídas as que dizem respeito às políticas editoriais científicas.

Sociologia \& Antropologia destina-se à apresentação, circulação e discussão de pesquisas originais que contribuam para o conhecimento dos processos socioculturais nos contextos brasileiro e mundial. Faz parte de sua missão, como se pode ler em nossa página oficial, valorizar as oportunidades de intercâmbio entre pontos de vista convergentes e divergentes nesses diferentes campos do conhecimento, mas de modo muito especial nos campos da sociologia e da antropologia. Essa é a proposta expressa pelo símbolo "\&", que, no título da revista, interliga as denominações de nossas duas disciplinas referenciais.

Diferente do que ocorreu tradicionalmente em outros contextos, no Brasil as três disciplinas das ciências sociais - antropologia, ciência política e so- 
ciologia - permanecem, desde suas origens universitárias na década de I930, ainda hoje bastante ligadas, não obstante vários processos de especialização disciplinar também perpassem suas histórias, sobretudo mais recentemente. No caso de Sociologia \& Antropologia, a revista aposta no relacionamento ativado pelo Programa de Pós-Graduação que a publica - hoje o único da região Sudeste a ter a nota máxima (7) de avaliação na Capes na área da sociologia - e que inspirou e tem inspirado outros programas no Brasil a investir nos diálogos intelectuais entre a sociologia e a antropologia.

O mapa que apresentamos é uma aposta nas metodologias informacionais. Como veremos, técnicas como as de acoplamento bibliográfico entre artigos e cocitação de autores nos ajudam a dar visibilidade e inteligibilidade a dados não apenas quantitativos, mas também qualitativos distintos daqueles produzidos por balanços bibliográficos tradicionais. Embora se trate de uma discussão em aberto, a emergência do chamado Big Data vem suscitando um amplo debate sobre os métodos e técnicas de pesquisa empírica nas ciências sociais (Burrows \& Savage, 20I4; Savage \& Burrows, 2007).

A integração da SciELO como uma das bases regionais da Web of Science (WoS) em 2014 (Vélez-Cuartas, Lucio-Arias \& Leydesdorff, 20I5) - certamente uma das principais bases de dados de artigos científicos no mundo - elevou a um novo patamar as perspectivas de exploração bibliométrica das publicações brasileiras em periódicos. Isso possibilitou a extração rápida e confiável dos principais metadados de cada artigo publicado na base SciELO - título, resumo, palavras-chave, data, instituição, referências bibliográficas etc. - e a modelagem das redes de interação entre artigos a partir de softwares como Pajek, VOSViewer e Gephi. Sem essas inovações fundamentais, tanto no plano das políticas científicas (Packer, 20I4) quanto no aperfeiçoamento de métodos e ferramentas de exploração bibliométrica (Cobo et al., 20I I), não seria viável esse tipo de distant reading da produção em artigos que está tensionando e mesmo redefinindo o tipo mais tradicional e assentado de balanço bibliográfico.

Para dimensionar o campo problemático em formação e as perspectivas em aberto por essas novas metodologias nas ciências humanas, mais do que simplesmente para ilustrar nosso argumento, vale rever brevemente algumas questões com as quais nos defrontamos numa de nossas experiências passadas com mapas, levantamentos e balanços bibliográficos qualitativos, isto é, a pesquisa que fizemos no âmbito das comemorações dos 40 anos da Associação Nacional de Pós-Graduação e Pesquisa em Ciências Sociais, a Anpocs, sobre os balanços bibliográficos promovidos pela própria entidade. ${ }^{\text {I }}$

$\mathrm{Na}$ segunda parte do texto apresentamos os dados sobre Sociologia \& Antropologia obtidos por meio de métodos informacionais e técnicas bibliométricas de análise. Essa estratégia não é aleatória, uma vez que desejamos justamente contrastar abordagens qualitativas (como as que são relatadas na primeira parte) e quantitativas (como as que realizamos na segunda), problematizando ganhos e perdas em um tipo ou outro. O contraste entre as abordagens, 
porém, em vez de sugerir a ideia de escolha entre uma delas e a exclusão da outra, quer antes reforçar nossa posição sobre a necessidade de mais ampla complementariedade entre as duas abordagens, até como forma de dar densidade a uma hermenêutica dos dados projetados computacionalmente.

\section{BALANÇOS BIBLIOGRÁFICOS: UM GÊNERO EM TRANSIÇÃO?}

Realizar balanços bibliográficos abrangentes e sistemáticos para mapear ou conhecer o estado da arte de uma área de conhecimento, de uma linha de pesquisa ou mesmo de um tema ou a trajetória de um conceito tornou-se hoje desafio sem precedentes, também nas ciências sociais - pelo inegável crescimento dessas disciplinas nas últimas décadas, no Brasil e no mundo, bem como pela multiplicação e relativa fragmentação dos suportes tradicionais de sua veiculação e publicação, notadamente do livro monográfico para o artigo publicado em periódicos científicos. Naturalmente, a incorporação cotidiana e crescente das ferramentas digitais ao trabalho acadêmico também aí desempenha seu papel decisivo. E com ambiguidade, sem dúvida, uma vez que ao mesmo tempo em que permite integrar imensa massa de dados e informações antes dispersas, seu caráter extremamente dinâmico também torna necessariamente inacabado todo o trabalho de recuperação, classificação e tratamento qualitativo dos dados.

Está-se indo embora, parece, o tempo em que balanços bibliográficos tradicionais, do tipo que resenhavam livros numa área de pesquisa, eram praticados e amplamente aceitos como retratos suficientemente válidos do estado da arte de um tema ou área de pesquisa. Atualmente, fazer balanços bibliográficos abrangentes tornou-se tarefa ainda mais arriscada, e exige muito tempo e espaço para evidenciar minimamente a pluralidade e a diversidade de abordagens, temas e questões presentes num universo virtualmente infinito, como o digital. Desafios do mesmo tipo têm levado a recortes que nem sempre dão uma ideia integrada de conjunto das áreas em pauta.

Em trabalho sobre os 40 anos da Anpocs (Botelho, Ricupero \& Brasil Jr., 20I7), discutimos um breve retrato das ciências sociais praticadas no Brasil a partir dessa Associação, analisando de modo mais detido justamente os balanços bibliográficos por ela diretamente induzidos ao longo dos últimos 20 anos para as áreas de sociologia e de ciência política. Notamos, primeiro, certas predominâncias temáticas e de enfoque teórico-metodológico que parecem exprimir as especificidades do modo pelo qual se deu a formação do Estado-nação e de uma comunidade política moderna no país. Segundo, e mais importante ainda para nosso tema hoje, a notável preocupação recorrente da Anpocs com a situação de suas disciplinas, pois ela tem sido pródiga na indução e mesmo promoção direta desse tipo de pesquisa e material bibliográfico. Suas atividades nessa direção incluem pelo menos dois materiais distintos: periódicos e coletâneas. No primeiro caso, incluem-se a Revista Brasileira de Ciências Sociais (RBCS), em cujas páginas podem-se encontrar diferentes balanços sobre a produção das 
disciplinas, de suas áreas de pesquisa e de seus temas ou fenômenos específicos, ainda que não se delineie em sua política editorial qualquer orientação específica nesse sentido. Mais significativo a esse propósito é um segundo periódico mantido pela Associação desde sua fundação, em I977, a Revista Brasileira de Informação Bibliográfica em Ciências Sociais (BIB). Como seu título sugere, a proposta editorial da BIB é justamente veicular balanços bibliográficos das áreas cobertas pelas ciências sociais, propósito com o qual se consolidou como uma das principais fontes de referência, sobretudo para estudantes de pós-graduação em fase de pesquisa. Uma terceira publicação da Associação, a Brazilian Review of Social Sciences (BRSS), cujos dois únicos números foram publicados em outubro de 2000 , também tem interesse para o problema em questão neste estudo, uma vez que, justamente por ser uma publicação em inglês, busca divulgar a produção das ciências sociais brasileiras num contexto de leitores mais amplo do que o lusófono.

Quanto às coletâneas, elas têm reunido sem dúvida balanços os mais exaustivos possíveis sobre áreas de pesquisas, temas e questões das disciplinas, escritos em geral por especialistas de renomada reputação acadêmica em suas respectivas áreas, ainda que em diferentes momentos da carreira. São elas: o anuário Ciências Sociais Hoje, publicado entre I980 e I996 com o intuito de reunir os melhores trabalhos apresentados nas reuniões anuais da Anpocs; os quatro volumes intitulados 0 que ler na ciência social brasileira, publicados os três primeiros em I999, o último em 2002; e, por fim, a coletânea em três tomos, como os três primeiros volumes da coletânea anterior também classificados por disciplinas (antropologia, ciência política e sociologia), publicada em 20 Io e intitulada Horizontes da Ciência Sociais no Brasil.

Essas coletâneas são particularmente importantes já que não constituem modalidades mais espontâneas de reflexão individual ou de um grupo de pesquisa localizado sobre o estado da arte de um tema; mas, antes, são encomendas que seguem objetivos e parâmetros mais amplos compartilhados institucionalmente numa política editorial da Associação sobre a produção acadêmica de suas disciplinas. Procuram, assim, reunir análises reflexivas e inéditas sobre a produção intelectual substantiva num conjunto de áreas temáticas relevantes, redigidas por cientistas sociais qualificados selecionados pela Associação junto aos organizadores das coletâneas. Como pudemos discutir no levantamento realizado para a comemoração dos 40 anos da Anpocs, os temas escolhidos em cada disciplina para objeto de levantamentos bibliográficos encomendados pela Associação encontram ressonância e correspondência (ainda que não estrita) com as trajetórias dos seus principais grupos de trabalhos (GTs). A título de esclarecimento, dos mais de 200 grupos de trabalho apresentados à Anpocs ao longo dos seus primeiros 40 anos, trabalhamos com 32 deles, que, nomeados igualmente (ou com poucas variações), estiveram presentes na Anpocs por pelo menos dez anos. 
Não estamos, obviamente, sugerindo que não exista mais interesse em balanços qualitativos de perfil mais restrito e tradicional, como esses que nós mesmos realizamos. Seu sentido, entretanto, parece, no mínimo, ter sido deslocado num mundo acadêmico informacional. Na verdade, o interesse por esse tipo de narrativa, prioritário ao efeito de verossimilhança mais ou menos pretendido, está hoje justamente nos seus limites.

São a precariedade com que inevitavelmente operam suas demarcações e sua tendência a lidar com procedimentos estabilizadores e cânones muito parciais, que implicam potencialmente a exclusão de propostas marginais aos grupos organizadores das revisões, que acabam por se tornar objeto de interesse. Afinal, nem sempre os balanços pretendem apontar necessariamente a teoria mais sofisticada ou ajuizar de alguma forma as diferentes posições em jogo, mas sempre permitem justamente captar tendências e, sobretudo, a formação de rotinas intelectuais num campo de debates no interior de uma área de pesquisa que vai, assim, se configurando e se transformando (Botelho \& Hoelz, 20I6). Interessante, a esse propósito, é a leitura atenta das introduções dos organizadores dos volumes, além dos autores dos artigos neles coligidos, nos quais toda sorte de procedimentos, códigos e convenções é mobilizada no sentido de justificar as escolhas inevitáveis nesse tipo de trabalho, sobre o que decidiram comentar ou o que ficou excluído. São peças retóricas ricas justamente na formação de rotinas intelectuais.

Essa espécie de close reading, para falar como Franco Moretti, não é, no entanto, toda a história. É possível substituir a leitura de perto por uma reflexão mais abrangente, vista de longe, uma espécie de, por contraste, distant reading: um "modo de trabalhar em que a distância não é um obstáculo, mas sim uma forma específica de conhecimento. A distância faz com que se vejam menos os detalhes, mas faz com que se observem melhor as relações, os pattern, as formas" (Moretti, 2008: 8). Em suma, o que deixamos de perceber mesmo quando olhamos tão de perto? Padrões, relações, formas, fundamentalmente. Então vamos a eles. ${ }^{2}$

\section{UMA DISTANT READING DE SOCIOLOGIA \& ANTROPOLOGIA}

Desde sua criação, em 20 I I, Sociologia \& Antropologia (S\&A) ambicionava alcançar, em curto e médio prazos, a excelência que caracteriza o Programa de Pós-Graduação em Sociologia e Antropologia, que a edita, o que compreenderia desde o projeto gráfico e a identidade visual, passando pela composição do Conselho Editorial e perfil dos colaboradores, a definição das normas editoriais e a criação de página na web para que a revista tivesse acesso efetivamente aberto, até a implementação de uma gestão editorial profissionalizada visando à qualificação, difusão e ao impacto por meio da indexação em bases conceituadas. Em pouco menos de dois anos Sociologia \& Antropologia receberia classificação BI no Qualis Periódicos da Capes e seria indexada nas bases CLASE, DOAJ, EBSCOHOST, Latindex, ProQuest e Sumários.org. Em cinco anos, a revista se adequaria às 
novas regras de internacionalização adotadas pelo SciELO em 20I5, tornando-se quadrimestral e passando a publicar também em inglês e, desde então, apenas em formato digital.

Em 2016 S\&A galgaria o estrato superior na avaliação da Capes, recebendo conceito AI, e passaria a integrar a Coleção SciELO, conquista essa bastante significativa tendo em vista que apenas $5 \%$ dos periódicos indexados na SciELO têm menos de I3 anos. ${ }^{3}$ Desde seu ingresso nessa base, Sociologia \& Antropologia vem atingindo regularmente as metas de internacionalização e de distribuição regional e institucional estabelecidas no que se refere tanto à composição do Conselho Editorial quanto à quantidade de artigos em inglês e à filiação institucional de autores e revisores, o que a destaca no cenário dos periódicos nacionais. A revista tem-se singularizado também por estabelecer diálogo permanente entre a sociologia e a antropologia, como discutido, e por promover o enriquecimento do debate nessas tradições disciplinares mediante a publicação de um conjunto de textos sobre autores relevantes, composto por entrevista e textos inovadores que operam com conceitos propostos pelo autor focalizado. Esse conjunto é publicado regularmente no primeiro e no último número de cada volume anual. Os seguintes autores já foram discutidos em entrevistas e textos inéditos publicados na revista: Max Weber, Claude Lévi-Strauss, Charles Tilly, Edward Sapir, Pierre Bourdieu, Victor Turner, David Harvey, Tim Ingold, Georg Simmel, Stephen Hugh-Jones, Karl Marx, Faye Ginsburg, Michel Foucault, Louis Dumont, Florestan Fernandes, Anthony Leeds, Jeffrey C. Alexander e, no número atual, Keith Hart. Desde 20I8, a revista encontra-se também na base Scopus e no início do corrente ano entrou em análise para inclusão na Web of Science.

A participação no limiar de uma década nesse empreendimento editorial nos tem impelido a uma reflexão sobre as condições do processo - desigual, mas combinado - de produção do conhecimento nas ciências sociais no Brasil em suas diferentes etapas - da captação de artigos, passando por sua avaliação e revisão, até a publicação, divulgação e citação/impacto. Mas também sobre os desafios constantes do trabalho propriamente intelectual envolvido na atividade editorial e o papel fundamental que os periódicos podem desempenhar não apenas na circulação e divulgação do conhecimento, mas na sua própria concepção, recepção e na indução de sua produção. De fato, tradicionalmente a publicação científica é vista como uma atividade de divulgação e apresentação de resultados de pesquisa, isto é, como se se situasse ao fim de uma espécie de cadeia produtiva do conhecimento. Lembrando ainda que, classicamente pela tradição culta ocidental, sobretudo nas ciências humanas, os artigos são vinculados aos livros.

Sendo também isso, artigos e periódicos científicos, porém, são sociologicamente bem mais do que isso. O que temos aprendido cada vez mais nos últimos anos na editoria de Sociologia \& Antropologia é ser preciso estender as concepções de artigos e periódicos científicos para além daquelas habitualmen- 
te assentadas. As proposições teóricas sobre a abordagem sociológica dos textos, como a de Don McKenzie (I999), Jerome McGann (I99I) e as de Roger Chartier (I997, 200I e 2002), de quem, aliás, já tivemos a oportunidade de publicar um artigo em Sociologia \& Antropologia (v. 2, n. 3, de 20I 2), podem aqui ser lembradas. Elas são decisivas para a percepção social mais ampla sobre como publicações (científicas) modelam de modo decisivo o horizonte de expectativas de leitores e a própria prática do conhecimento (a pesquisa). Como mostra a sociologia dos textos de D. F. McKenzie (I999), por exemplo, não apenas a forma de um texto é crucial na composição de seu sentido, como à medida que textos são reproduzidos, reeditados e relidos assumem diferentes formas e significados. Textualidade e materialidade da escrita estão intimamente associadas, assim como também forma e conteúdo constituem uma relação indissociável. ${ }^{4}$

Aproveitando a deixa de McKenzie, para quem a articulação entre texto e paratexto - índices, ilustrações, notas, tabelas - forma instâncias atuantes nos significados interpretáveis que modelam a leitura, trazemos agora, enfim, alguns dados importantes para compartilhar com nossos leitores a reflexão sobre os nove anos cumpridos de publicação de Sociologia \& Antropologia.

Esses dados incluem tanto informações dos autores, como filiação institucional (e localização espacial), dos próprios textos, como o idioma de publicação, e especialmente das conexões estabelecidas pelos textos de Sociologia \& Antropologia entre si, por meio de técnicas bibliométricas como a análise de cocitação e de acoplamento bibliográfico. A produção desses dados, como advertimos no início do texto, foi possível graças à integração da base SciELO como uma das coleções regionais da Web of Science, garantindo a extração rápida e confiável dos metadados (nome dos autores, instituições, idioma de publicação, palavras-chave etc.) e das referências bibliográficas de toda a coleção de Sociologia \& Antropologia.

Em primeiro lugar, vamos à distribuição geográfica dos autores da revista. Em relação à sua distribuição entre países - considerados do ponto de vista da filiação institucional do autor, e não de seu país de nascimento -, vemos uma natural concentração no Brasil (2 I3 autores), como era de esperar. Logo em seguida, as principais contribuições vêm de dois países centrais das ciências sociais: França (I9) e Estados Unidos (I8). Apesar da presença significativa de autores situados na Argentina (I 2), o baixo número de contribuições dos demais países da América Latina indica que se trata de um desafio para S\&A estimular uma frente de cooperação nessa direção - a adoção do espanhol como idioma de publicação nesta edição é indicador de que estamos caminhando nessa direção. 


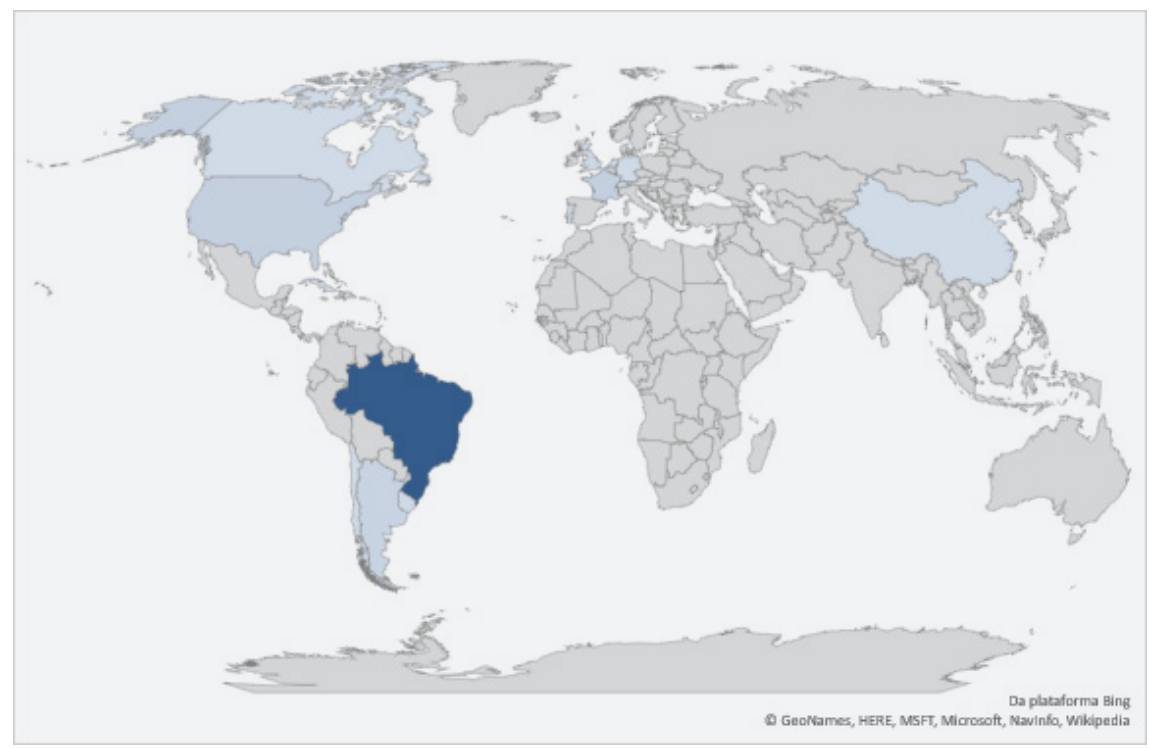

Figura I

Distribuição geográfica (por países) dos autores de S\&A (afiliação institucional dos autores) Fonte: SciELO/WoS

$\begin{array}{ll}\text { PAÍSES/REGIÕES } & \text { ARTIGOS } \\ \text { Brasil } & 2 \text { I3 } \\ \text { França } & \text { I9 } \\ \text { Estados Unidos } & \text { I8 } \\ \text { Argentina } & \text { I2 } \\ \text { Portugal } & 7 \\ \text { Reino Unido } & 4 \\ \text { Uruguai } & 2 \\ \text { Alemanha } & 2 \\ \text { Canadá } & \text { I } \\ \text { Chile } & \text { I } \\ \text { China } & \text { I } \\ \text { Cuba } & \text { I } \\ \text { Holanda } & \text { I } \\ \text { Suíça } & \text { I }\end{array}$

Tabela I

Distribuição geográfica (por países) dos autores de S\&A (afiliação institucional dos autores) Fonte: SciELO/WoS 
Em termos de distribuição por instituições brasileiras, vemos, como também seria de esperar, uma concentração no eixo Rio-São Paulo, o que exprime as desigualdades estruturantes da produção científica brasileira, em geral, e nas ciências sociais, em particular. Vale registrar, porém, a razoável dispersão entre instituições sediadas nas regiões Sudeste, Sul e Nordeste, a despeito da urgente necessidade de maior descentramento em relação ao Sudeste. Ainda um desafio para S\&A é a inclusão de mais instituições das regiões Centro-Oeste e Norte, que estão praticamente descobertas à exceção dos casos do Pará e do Distrito Federal.

\section{Figura 2}

Distribuição geográfica (por estados brasileiros) dos autores de S\&A

(afiliação institucional dos autores)

Fonte: SciELO/WoS 


\begin{tabular}{|c|c|c|}
\hline INSTITUIÇÕES & REGISTROS & ESTADO \\
\hline UNIVERSIDADE FEDERAL DO RIO DE JANEIRO & 65 & RJ \\
\hline UNIVERSIDADE DE SÃO PAULO & 33 & SP \\
\hline UNIVERSIDADE ESTADUAL DE CAMPINAS & 27 & SP \\
\hline UNIVERSIDADE DO ESTADO DO RIO DE JANEIRO & 20 & RJ \\
\hline UNIVERSIDADE FEDERAL FLUMINENSE & I2 & RJ \\
\hline UNIVERSIDADE FEDERAL DO RIO GRANDE DO SUL & 7 & RS \\
\hline FUNDAÇÃO OSWALDO CRUZ & 6 & RJ \\
\hline FUNDAÇÃO GETULIO VARGAS & 5 & RJ \\
\hline PONTIFÍCIA UNIVERSIDADE CATÓLICA DO RIO DE JANEIRO & 5 & RJ \\
\hline UNIVERSIDADE DE BRASÍLIA & 5 & $\mathrm{DF}$ \\
\hline UNIVERSIDADE FEDERAL DE SÃO CARLOS & 5 & SP \\
\hline UNIVERSIDADE FEDERAL DE MINAS GERAIS & 5 & MG \\
\hline UNIVERSIDADE FEDERAL RURAL DO RIO DE JANEIRO & 4 & RJ \\
\hline UNIVERSIDADE FEDERAL DE JUIZ DE FORA & 3 & MG \\
\hline UNIVERSIDADE FEDERAL DO PARÁ & 3 & PA \\
\hline UNIVERSIDADE FEDERAL DA BAHIA & 2 & BA \\
\hline UNIVERSIDADE FEDERAL DO PARANÁ & 2 & $\mathrm{PR}$ \\
\hline CENTRO DE ESTUDOS DE CULTURA CONTEMPORÂNEA & I & SP \\
\hline CENTRO ESTADUAL DE EDUCAÇÃO TECNOLÓGICA PAULA SOUZA & I & SP \\
\hline CENTRO FEDERAL DE EDUCAÇÃO TECNOLÓGICA DO RIO DE JANEIRO & I & RJ \\
\hline INSTITUTO BRASILIENSE DE DIREITO PÚBLICO & I & $\mathrm{DF}$ \\
\hline PONTIFÍCIA UNIVERSIDADE CATÓLICA DE SÃO PAULO & I & SP \\
\hline PONTIFÍCIA UNIVERSIDADE CATÓLICA DO RIO GRANDE DO SUL & I & RS \\
\hline SÃO PAULO FACULTY OF TECHNOLOGY & I & SP \\
\hline UNIVERSIDADE FEDERAL DE CAMPINA GRANDE & I & PB \\
\hline UNIVERSIDADE FEDERAL DE PERNAMBUCO & I & $\mathrm{PE}$ \\
\hline UNIVERSIDADE FEDERAL DE SANTA CATARINA & I & SC \\
\hline UNIVERSIDADE FEDERAL DE SANTA MARIA & I & RS \\
\hline UNIVERSIDADE FEDERAL DE SERGIPE & I & $\mathrm{SE}$ \\
\hline UNIVERSIDADE FEDERAL DO ABC & I & SP \\
\hline UNIVERSIDADE FEDERAL DO CEARÁ & I & $\mathrm{CE}$ \\
\hline UNIVERSIDADE FEDERAL DO ESPÍRITO SANTO & I & ES \\
\hline UNIVERSIDADE FEDERAL DO MARANHÃO & I & MA \\
\hline UNIVERSIDADE VILA VELHA & I & ES \\
\hline
\end{tabular}

Tabela 2

Distribuição geográfica (por estados brasileiros) dos autores de S\&A

(afiliação institucional dos autores)

Fonte: SciELO/WoS 
S\&A tem feito esforços consistentes no sentido de promover canais de internacionalização da produção em ciências sociais no Brasil. Um desses canais se expressa no idioma de publicação. Quase I/5 dos textos publicados na revista saiu em inglês, preferencialmente textos de autores brasileiros vertidos para esse idioma, na expectativa de aumentar o impacto de nossa produção em outros contextos nacionais. Mais recentemente, estamos incluindo também textos de autores com afiliação estrangeira em inglês, revelando a progressiva integração de S\&A aos principais circuitos de publicação em ciências sociais no mundo.

Por fim, um último indicativo relevante, em relação aos aspectos demográficos da população de autores de S\&A, é sua distribuição por gênero. A distribuição encontrada $-56 \%$ de homens e $44 \%$ de mulheres como primeiros autores - indica, é certo, um desequilíbrio (embora não muito pronunciado) entre os gêneros, que deverá ser levado em conta para os próximos dez anos da revista e, na medida do possível. corrigido belo trabalho editorial.

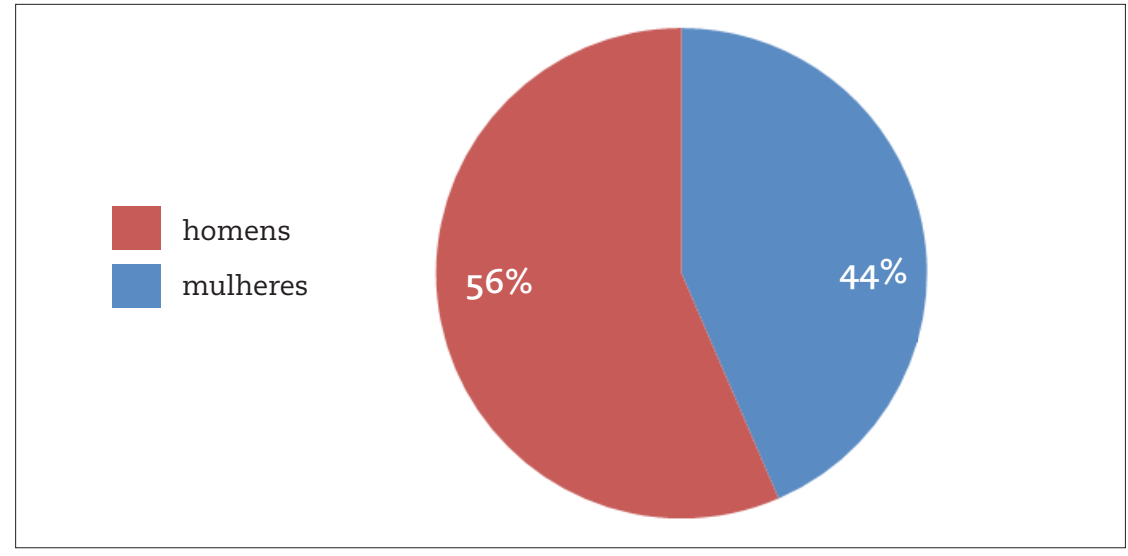

Figura 3

Distribuição da autoria dos artigos de S\&A por gênero, considerando os primeiros autores.

Fonte: Elaboração própria dos autores.

Como vem sendo discutido no campo interdisciplinar dos estudos cientométricos, as citações científicas criam relações em dois níveis interligados, mas distintos. De um lado, elas revelam citações entre autores ou instituições, isto é, criam redes sociais entre atores científicos que se citam (mutuamente ou não). De outro, as citações igualmente estabelecem conexões entre textos, ou melhor, criam redes textuais como subproduto da atividade citante dos produtores de artigos científicos, livros etc. Dito de outra maneira, a prática rotineira de citação de autores produz simultaneamente, em um nível reflexivo e emergente, uma rede de textos que se ligam entre si, com graus distintos de intensidade, a depender da variável relacional escolhida (Leydesdorff, I998). Uma técnica há muito utilizada, para esse fim, é o acoplamento bibliográfico, que nada mais é senão uma 
matriz de similaridade entre artigos que mensura o quanto cada texto compartilha com outro referências bibliográficas (Weinberg, I974). Quanto maior o grau de compartilhamento, maior o peso das relações entre os textos (e vice-versa). Essa matriz fundamenta a modelagem de uma rede entre textos, em que a proximidade ou o afastamento de seus diferentes "nós" (os artigos) exprime justamente o maior ou menor peso de suas "arestas" (a intensidade do compartilhamento de referências), conforme a notação que se convencionou utilizar na network theory (Borgatti \& Halgin, 20I I).

A técnica do acoplamento bibliográfico possibilita situar S\&A no interior das ciências humanas brasileiras e, mais especificamente, nas ciências sociais aqui praticadas. A fim de termos um contexto comparativo, extraímos igualmente as referências completas de toda a coleção SciELO "Ciências Humanas" entre 2002 e 2019 e classificamos as 90 revistas que integram essa coleção em áreas disciplinares. ${ }^{5} \mathrm{Na}$ imagem abaixo, vemos os artigos de S\&A (em preto e em destaque) acoplados bibliograficamente na região nordeste da rede de artigos formada por essa coleção, ${ }^{6}$ integrando-se mais fortemente às publicações de ciências sociais (em verde) e de antropologia (em roxo), com alguma abertura para as áreas de história (em laranja) e ciência política (em amarelo). Por outro lado, os artigos de S\&A se desacoplam com maior nitidez, como esperado, das áreas de psicologia (em rosa), de saúde pública (em vermelho) e das revistas interdisciplinares (em azul escuro). Porém, esse contexto mais geral nos faz perder as especificidades de S\&A no interior das ciências sociais, onde ela efetivamente se localiza.

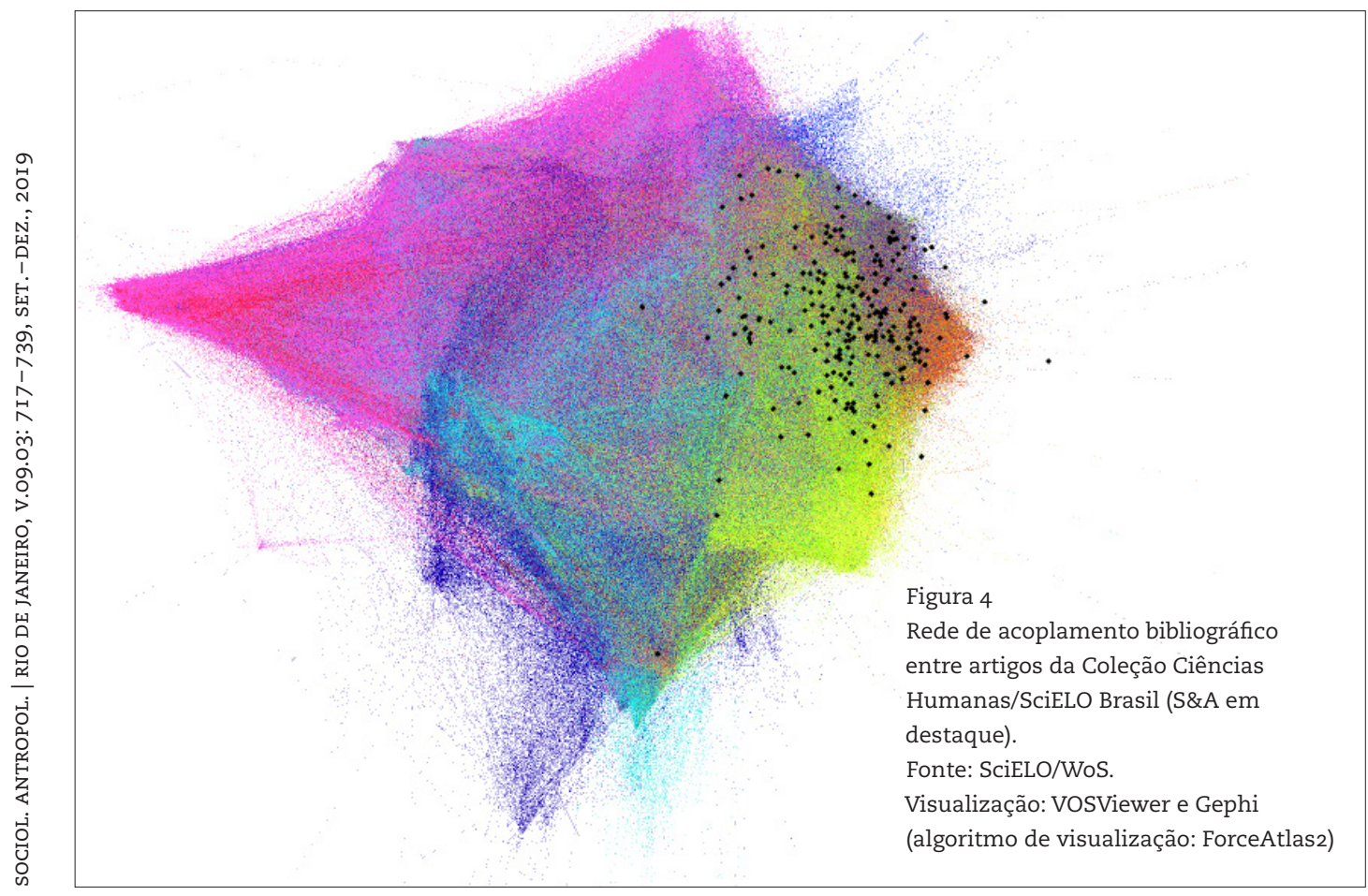


Por essa razão, fizemos outro experimento detectando as formas de acoplamento bibliográfico de S\&A no contexto de I5 publicações em ciências sociais na base SCiELO no mesmo período. Isso nos permite visualizar como os artigos de S\&A se acoplam ou se desacoplam em relação aos demais periódicos científicos das ciências sociais, embora esse exercício não tenha qualquer pretensão de uma investigação exaustiva. Podemos fazer essa análise de acoplamento usando diferentes unidades de análise: a partir dos artigos (como fizemos acima) ou tomando a própria revista como unidade. No último caso, apesar de aplainar as muitas arestas internas a cada publicação, o acoplamento bibliográfico entre revistas tem a vantagem de permitir a visualização da posição estrutural de cada periódico a partir de suas referências compartilhadas. Na próxima imagem, usamos o algoritmo de detecção de comunidades [modularity class] a fim de calcular quais revistas possuem maior probabilidade de compartilhar referências no interior do conjunto por elas formado (Blondel, 2008) - estabeleceram-se duas comunidades, uma "socioantropológica", em vermelho, e uma "sociopolítica", em verde. Houve ainda uma partição relativa entre as regiões à direita e à esquerda da parte superior da rede, formadas grosso modo por publicações da ciência política e da antropologia, respectivamente; e outra partição entre os segmentos superior e inferior, com as revistas de sociologia e/ou ciências sociais se concentrando de modo mais nítido no último. Observa-se que S\&A, como era de esperar, está localizada na comunidade "socioantropológica" e, na topologia da rede, opera um papel de mediação entre as publicações da antropologia e as da sociologia e/ou ciências sociais - daí sua posição ao centro e deslocada à esquerda.

Figura 5

Rede de acoplamento bibliográfico entre revistas de ciências sociais. Fonte: SciELO/WoS.

Visualização: VOSViewer e Gephi (algoritmo de visualização: ForceAtlas2)

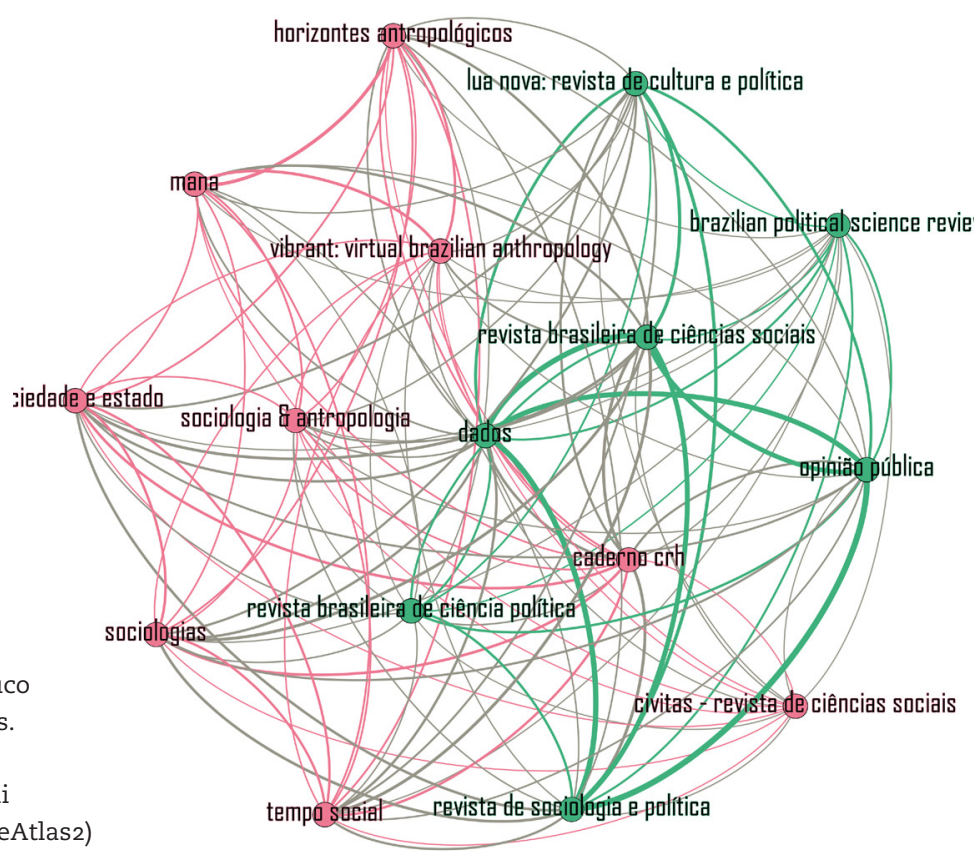


Se quisermos agora descer ao nível dos artigos - o que permite capturar a heterogeneidade interna às publicações -, vemos destacados (em preto) na imagem abaixo os artigos de S\&A no contexto dos demais artigos das 15 revistas. Os artigos das revistas de antropologia estão em azul, e os veiculados em periódicos da ciência política, em vermelho - polarizando a rede em seu eixo horizontal. Mediando as duas áreas, estão os artigos de revistas que reúnem sociologia e ciência política (em laranja), os das revistas de ciências sociais (em verde) e os que estão em publicações mais estritamente sociológicas (em amarelo). Verificamos evidente concentração dos artigos de S\&A à esquerda, fruto de seu significativo acoplamento com textos publicados em revistas da antropologia; por outro lado, há significativa presença dos artigos de S\&A nas áreas em que se situam as revistas de sociologia e de ciências sociais, além de ser possível identificar algum acoplamento com os textos dos periódicos da ciência política. O dado que mais chama nossa atenção, porém, é a densidade da concentração dos artigos de S\&A justamente na fronteira entre a antropologia e a sociologia/ciências sociais, o que demonstra o sucesso de nosso empreendimento editorial - voltado para a comunicação e irritação mútua entre essas disciplinas - e, além disso, a posição estrutural única da revista na publicação científica brasileira.

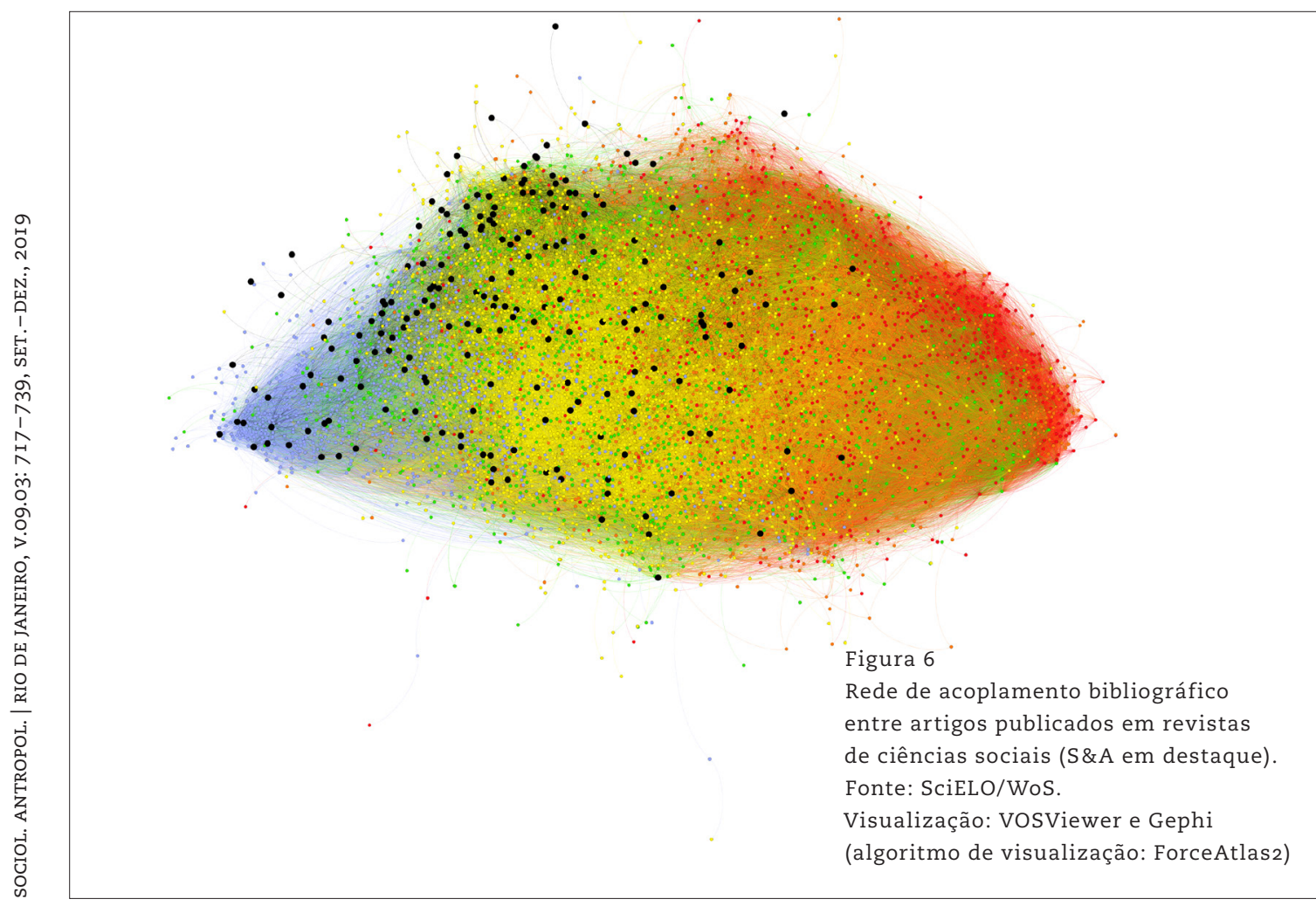


Outra técnica comumente usada nos estudos cientométricos é a análise de cocitação (White \& Griffith, I98I). Trata-se de estabelecer relações entre dois autores citados em um mesmo documento - no nosso caso, nos artigos de S\&A. Quanto maior a citação de um autor, maior o tamanho do "nó" que ele representa; e quanto mais frequentemente um autor aparece citado ao lado de outro, maior é a espessura da "aresta" que representa graficamente suas relações. Abaixo, temos visíveis os nomes de todos os autores citados pelo menos dez vezes em S\&A - a rede subjacente foi criada a partir da ocorrência mínima de três vezes. Encontramos uma notável mescla de generalidade e especificidade aqui: temos tanto os autores que costumam ser muito citados nas ciências sociais brasileiras - em particular, Bourdieu, Foucault e os autores "clássicos" - quanto alguns nomes menos óbvios, que ganharam destaque em função dos números especiais em torno de certos autores da sociologia e da antropologia. São os casos, por exemplo, de Georg Simmel (embora clássico, não costuma ser tão citado quanto Weber, Marx e Durkheim), Jeffrey Alexander, Victor Turner, Anthony Leeds, Florestan Fernandes, entre outros. Esse esforço ativo de discutir de modo qualificado, reunindo especialistas brasileiros e estrangeiros, autores fundamentais (tanto os mais citados quanto outros menos lembrados atualmente) das nossas ciências sociais tem sido uma das marcas fundamentais de S\&A.

Figura 7

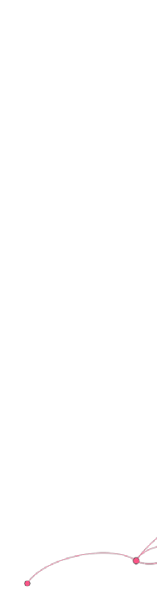

Rede de com citação de autores, com destaque para os autores citados pelo menos Iox.

Fonte: SciELO/WoS.

Visualização: VOSViewer e Gephi

(algoritmo de visualização: ForceAtlas2) 
Por fim, também podemos ensaiar aqui uma leitura distante, na verdade lexical, do conteúdo dos artigos de S\&A por meio de seus resumos. A análise fatorial de correspondência (AFC) é técnica estatística que permite identificar uma estrutura latente em uma totalidade de relações na qual múltiplas variáveis agem concomitantemente. Cada uma dessas variáveis recebe um valor específico, e a proximidade entre elas cria conjuntos de variáveis aos quais correspondem os dois eixos do plano fatorial. O gráfico de análise de correspondência abaixo foi gerado pelo software Iramuteq, interface para análise textual do pacote estatístico $R$, e mostra como as categorias mais recorrentes dos resumos se aproximam e se distanciam umas das outras conforme a força gravitacional dos eixos (Camargo \& Justo, 2013). Dada essa proximidade entre as categorias, o software estipula comunidades, distinguidas pelas cores. Vemos no plano fatorial abaixo quatro quadrantes e seis comunidades, revelando concentrações e dispersões vocabulares nos resumos de S\&A. Nos dois quadrantes à direita, nas cores cinza, verde e azul, percebemos nas regiões superior e inferior termos claramente vinculados ao debate em teoria sociológica e teoria antropológica, respectivamente, debate promovido sobretudo (embora não exclusivamente) por nossos números especiais dedicados a certos autores-chave de nossas disciplinas. Nos dois quadrantes à esquerda, nas cores azul-claro, rosa e vermelho, vemos uma ampla gama de termos que descrevem temas de pesquisa, com destaque para as categorias ligadas aos estudos urbanos, aos mercados, aos trabalhadores, à produção cultural (incluindo museus, modernismo, musical, artista etc.), à memória, à família, entre outros, incluindo igualmente marcadores espaciais, como regional, nacional, brasileiro, Portugal e africanos. A análise dos termos revela, de novo, a combinação de generalidade (os termos são comuns às ciências sociais aqui praticadas) e de especificidade (há forte presença dos termos ligados à produção teórico-intelectual e à pesquisa sobre a cultura em S\&A). Talvez seja mesmo uma marca de S\&A, por sua iniciativa de interpenetrar sociologia e antropologia, promover um rico debate, ao mesmo tempo teórico e empírico, plural e descentrado, sobre as formas simbólicas da vida social e suas conexões com as práticas e os processos sociais. 


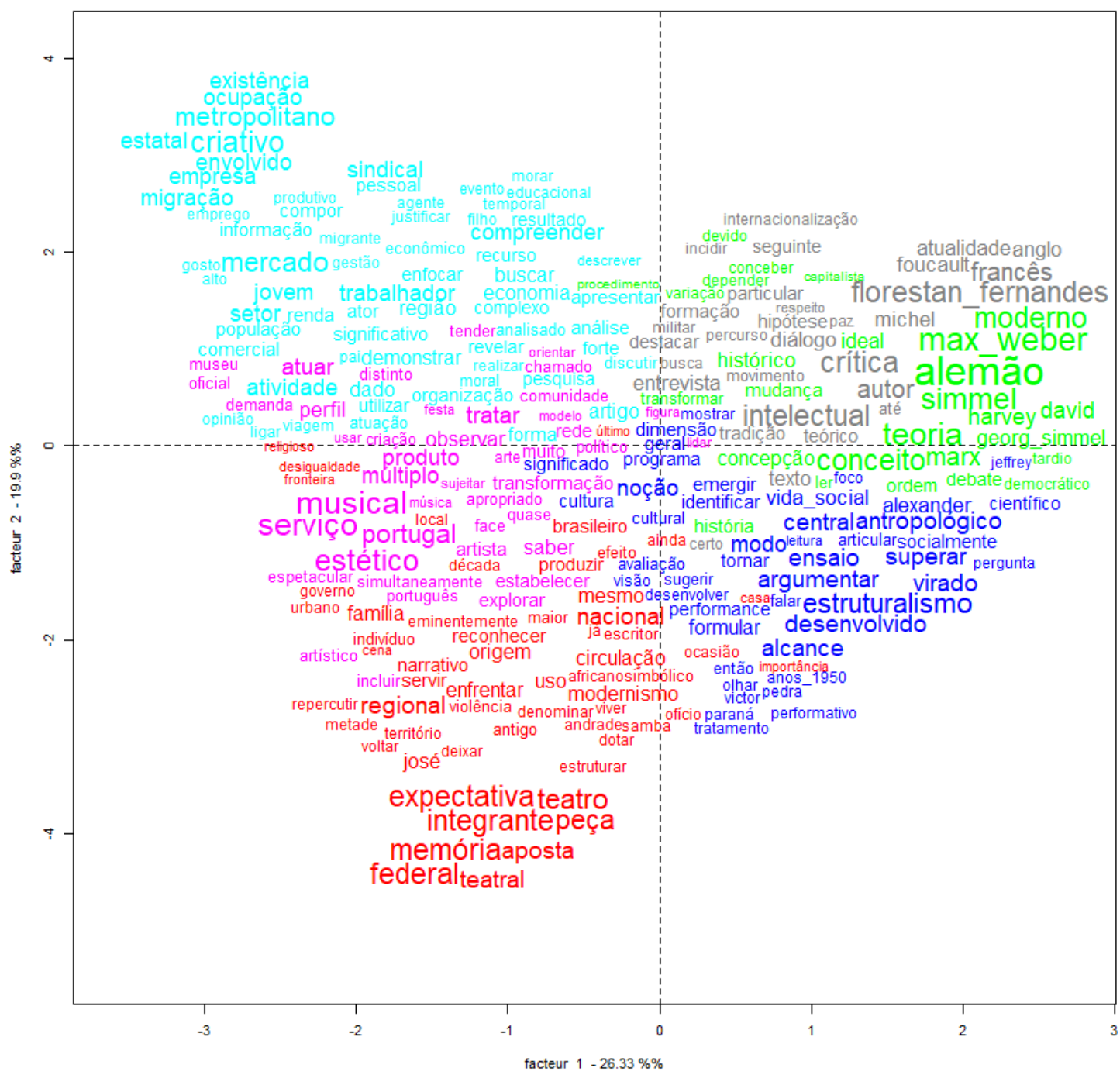

Figura 8

Análise Fatorial de Correspondência

por Classificação Hierárquica

Descendente dos resumos dos artigos

de $\mathrm{S} \& \mathrm{~A}$.

Fonte: Base SciELO/WoS.

Visualização: Iramuteq

Ao concluir este texto, aproveitamos a oportunidade para anunciar mudanças na gestão direta de Sociologia \& Antropologia a partir do próximo número, a ser publicado em 2020. 
André Botelho, editor responsável nos últimos dois anos (2018-20I9) e editor desde o início, em 2009, se despede da editoria da revista. Antonio Brasil Jr., editor desde 20I8, passará a responder a partir do próximo número como editor responsável. Maurício Hoelz que, trabalhando conosco desde 2007-2008 no projeto que originou a revista, já tendo passado pelas funções de assistente editorial e de editor executivo, passa à de editor associado já no presente número.

Despedem-se da editoria, também, as colegas Maria Laura Viveiros de Castro Cavalcanti, a editora responsável anterior de Sociologia \& Antropologia (20I5-20I7) e Elina Pessanha, editora desde o início da revista. Os três editores, Botelho, Cavalcanti e Pessanha, passarão a integrar a Comissão Editorial da revista.

É o momento, então, de alguns agradecimentos em nome de toda a equipe editorial atual. Em primeiro lugar aos autores e autoras, revisores e revisoras (pareceristas), leitores e leitoras de Sociologia \& Antropologia que têm conferido sentido a uma aventura tão estimulante quanto desafiadora, como a de criar e editar um periódico científico de excelência na área das ciências humanas no Brasil da última década. Comprometida, sobretudo, com o debate teórico da sociologia e da antropologia, a revista tem conquistado seguidores nesta última década, no curso da qual se tornou referência nas ciências sociais.

Agradecemos também à Comissão Editorial da revista, composta por Els Lagrou, Glaucia Villas Bôas, nossa primeira editora responsável (2009-20I4), José Reginaldo Gonçalves e José Ricardo Ramalho. Nomeando-os, pensamos em cada um dos membros do colegiado do PPGSA nos últimos dez anos e lhes agradecemos a confiança com que nos entregaram o desafio de compartilhar, a partir de uma publicação científica, a marca distintiva do nosso programa e o relacionamento entre as duas disciplinas que o compõem. Estudantes e egressos do PPGSA têm igualmente deixado sua marca em nossa história.

Queremos agradecer ainda aos membros do Conselho Editorial que em diferentes momentos, alguns delicados, nos auxiliaram diretamente com orientações, mas também souberam celebrar conosco cada uma de nossas conquistas. Nomeando Charles Pessanha, referência incontornável na história dos periódicos científicos no Brasil, estendemos nossos agradecimentos a todo o Conselho Editorial. E também aos colegas editores de outros periódicos científicos do Brasil e do exterior, especialmente das ciências sociais, pela interlocução permanente tão importante para Sociologia \& Antropologia. No mesmo sentido, consignamos nosso reconhecimento pelo trabalho crucial, e desafiador, desenvolvido pelo SciELO na garantia do acesso aberto no Brasil.

Por fim, mas não menos importante, devemos um agradecimento muito especial aos que integram e integraram a equipe de assessoria técnica de Sociologia \& Antropologia nesses anos: à designer Glória Afflalo, às revisoras Maria 
Helena Torres, Beth Cobra; e também aos assistentes editoriais Carlos Douglas Martins, Guilherme Marcondes, José Luiz Soares e Maurício Hoelz.

A partir do próximo número Antonio Brasil Jr e Marco Antonio Gonçalves assumem a editoria de Sociologia \& Antropologia. Rodrigo Santos e Julia O'Donnell continuarão o importante trabalho de assistência editorial que já vêm realizando no último ano. A eles se junta, como dissemos, Maurício Hoelz agora na condição de editor associado. Desejamos à nova equipe toda fortuna e força para enfrentar os muitos desafios que se anunciam também para as publicações científicas neste momento.

Recebido em I/Io/20I9 | Aprovado em I6/Io/20I9

André Botelho é professor-associado do Departamento de Sociologia e do Programa de Pós-Graduação em Sociologia e Antropologia da Universidade Federal do Rio de Janeiro. Editor responsável de Sociologia \& Antropologia, é ainda pesquisador (IC) do CNPq e Cientista do Nosso Estado da Faperj. Autor, entre outros, de O retorno da sociedade. Política e interpretações do Brasil (Vozes, 2019).

Antonio Brasil Jr. é professor adjunto do Departamento de Sociologia e do Programa de Pós-graduação em Sociologia e Antropologia da Universidade Federal do Rio de Janeiro. Editor de Sociologia \& Antropologia. Jovem Cientista do Nosso Estado (JCNE/Faperj). É autor de Passagens para a teoria sociológica (2013).

Maurício Hoelz é professor adjunto do Departamento de Ciências Sociais da Universidade Federal Rural do Rio de Janeiro. Editor associado de Sociologia \& Antropologia. É autor de A violência que nos une (no prelo). 


\section{NOTAS}

I Criada em I977 no contexto de formulação de um programa nacional de pós-graduação como política pública de Estado, a Anpocs conta hoje com mais de Ioo instituições de ensino de pós-graduação e de pesquisa como associados. Desde sua fundação, a Associação vem realizando encontros anuais que, especialmente a partir de seus Grupos de Trabalho, organizam parcela considerável dos debates dessas três disciplinas no Brasil. Sua centralidade na comunidade científica das ciências sociais também se evidencia pelo esforço contínuo com que vem promovendo reflexões e balanços bibliográficos das várias áreas disciplinares, e esse material permite traçar um painel bastante representativo da produção acadêmica brasileira.

2 Alguns dados gerais aqui trabalhados foram inicialmente apresentados em comunicação de Antonio Brasil e André Botelho na mesa-redonda "Balanços bibliográficos em questão", no encontro da Anpocs de 2018.

3 Ver <https://blog.scielo.org/>.

4 A própria equiparação da intenção autoral à autoridade textual na atividade editorial é um processo histórico e dinâmico, como sugere McKenzie (I999). Hoje, a concepção de autor como entidade unitária vem sendo problematizada crescentemente pela percepção de um processo complexo que envolve etapas como as primeiras revisões do autor, as revisões editoriais, a realização das provas, a publicação, a reimpressão. São, portanto, as relações entre elementos do próprio texto e entre este e diferentes atores sociais - leitores e editores-, bem como com convenções intelectuais e linguísticas de uma época, que constroem o significado de um texto.

5 Esse trabalho foi realizado em parceria por Lucas Carvalho (UFF) e Antonio Brasil Jr. (UFRJ) para artigo ainda não publicado dedicado à análise da coleção de artigos de ciências humanas da base SciELO.

6 Para fins de cálculo e visualização, os artigos com pouco ou nenhum compartilhamento de referências com os demais textos da coleção são excluídos da rede de acoplamento bibliográfico. A advertência deve ser feita também com relação à outra imagem de rede aqui apresentada. Ou seja, trabalhamos aqui apenas com a "componente principal" [giant componente] da rede de acoplamento bibliográfico formada pelos artigos selecionados. 


\section{REFERÊNCIAS BIBLIOGRÁFICAS}

Blondel, V. D. et al. (2008). Fast unfolding of communities in large networks. Journal of Statistical Mechanics: Theory and Experiment, I0, p. PIooo8.

Borgatti, S. P. \& Halgin, D. S. (20II). On Network Theory. Organization Science, 22/5, p. II68-II8I.

Botelho, A. \& Hoelz, M. (2016). Sociologias da literatura: do reflexo à reflexividade. Tempo Social, 28/3, p. 263-287.

Botelho, A.; Ricupero, B.; Brasil Jr., A. (20I7). Cosmopolitism and localism in the Brazilian social sciences. Canadian Review of Sociology/Revue canadienne de sociologie, 54/2, p. $216-236$.

Burrows, R. \& Savage, M. (20I4). After the crisis? Big Data and the methodological challenges of empirical sociology. Big Data \& Society, I/I, p. 205395 I7I4540280.

Burt, R. S. (2009). Structural holes: the social structure of competition. [s.l.]: Harvard University Press.

Camargo, B. V. \& Justo, A. M. (2013). Iramuteq: um software gratuito para análise de dados textuais. Temas em psicologia, 2I/2, p. 513-518.

Chartier, R. (2002). Os desafios da escrita. Trad. M. L. Moretto. São Paulo: Edunesp.

Chartier, R. (200I). Práticas de leitura. Trad. Cristiane Nascimento. 2 ed. São Paulo: Estação Liberdade.

Chartier, R. (1997). A ordem dos livros. Trad. Leonor Graça. Lisboa: Vega.

Cobo, M. J. et al. (20II). Science mapping software tools: review, analysis, and cooperative study among tools. Journal of the American Society for Information Science and Technology, 62/7, p. I382-I402.

Leydesdorff, L. (I998). Theories of citation? Scientometrics, 43/I, p. 5-25.

McGann, J. Jerome. (I99I). The textual condition. Princeton: Princeton University Press.

McKenzie, D. F. (I999). Bibliography and the sociology of texts. London: Cambridge University Press.

Moretti, Franco. (2008). A literatura vista de longe. Porto Alegre: Arquipélago Editorial. 
TÃO LONGE, TÃO PERTO: SOCIOLOGIA \& ANTROPOLOGIA NO LIMIAR DE UMA DÉCADA

738

Packer, A. L. (2014). SciELO Citation Index no Web of ScienceSCiELO em Perspectiva. Disponível em: <https://blog.scielo.org/blog/20I4/o2/28/scielo-citation-index-no-web-of-science/>. Acesso em I4 mar. 2019.

Savage, M. \& Burrows, R. (2007). The coming crisis of empirical sociology. Sociology, 4I/5, p. 885-899.

Vélez-Cuartas, G.; Lucio-Arias, D. \& Leydesdorff, L. (2015). Regional and global science: Latin American and Caribbean publications in the SciELO Citation Index and the Web of Science. arXiv preprint arXiv:I510.02453.

Weinberg, B. H. (I974). Bibliographic coupling: a review. Information Storage and Retrieval, I0/5, p. I89-I96.

White, H. D. \& Griffith, B. C. (I98I). Author cocitation: a literature measure of intellectual structure. Journal of the American Society for Information Science, 32/3, p. I63-I7I. 


\section{Palavras-chave \\ Sociologia \& Antropologia; Periódicos científicos; \\ Análise bibliométrica;}

Big data;

Distant reading.

Keywords

Sociology \& Anthropology;

Scientific journals;

Bibliometric analysis;

Big data;

Distant reading
TÃO LONGE, TÃO PERTO: SOCIOLOGIA \& ANTROPOLOGIA NO LIMIAR DE UMA DÉCADA Resumo

O texto apresenta um mapa semântico e bibliométrico da coleção de artigos de Sociologia \& Antropologia. Revista do PPGSA realizado a partir de metodologias informacionais. Publicada pelo Programa de Pós-graduação em Sociologia e Antropologia da Universidade Federal do Rio de Janeiro, desde 201 I, a revista se vem consolidando como um dos periódicos mais importantes de veiculação da produção científica de ponta das ciências sociais no Brasil. Ao mesmo tempo em que registra e reflete sobre a nossa publicação na última década, oferecendo uma visão de conjunto dos artigos, o mapa que apresentamos é também uma aposta no chamado Big Data no debate mais amplo sobre os métodos e técnicas de pesquisa nas ciências sociais.

SO FAR, SO NEAR: SOCIOLOGIA \& ANTROPOLOGIA ON THE THRESHOLD OF A DECADE

Abstract

The text presents a semantic and bibliometric map of the collection of articles published by Sociologia \& Antropologia. Revista do PPGSA, making use of information methodologies. Published by the Postgraduate Program in Sociology and Anthropology of the Universidade Federal do Rio de Janeiro since $20 \mathrm{II}$, the journal has become established as one of the most important periodicals for disseminating the latest scientific production in the social sciences in Brazil. At the same time as registering and reflecting on our publication over the last decade, offering an overview of the articles, the map presented here also explores the potential of so-called Big Data in the broader debate on research methods and techniques in the social sciences. 